\title{
Prevalence of metabolic syndrome in Psoriasis - a case control study
}

\author{
K.V.T. Gopal ${ }^{1}$, G. Deepika Raj ${ }^{2}$, T. Narayana Rao ${ }^{3}$ \\ ${ }^{1}$ Dr. K.V.T.Gopal, ${ }^{2}$ Dr. G. Deepika Raj, ${ }^{3}$ Dr T. Narayana Rao, Department of Dermatology, Maharajah's Institute of Medical \\ Sciences, Nellimarla, Vizianagaram Dt., Andhra Pradesh, India.
}

Address for Correspondence: Dr. K.V.T.Gopal, Associate Professor of Dermatology, MIMS, Res: 4-69-19, Opp. Shanti Ashram Street, Lawsons Bay Colony, Visakhapatnam. Email: kvtgopal@yahoo.co.in

\begin{abstract}
Introduction: Recently, associations between psoriasis and metabolic disorders such as obesity, diabetes, and atherogenic dyslipidemia have been recognized. The present study was performed to know the prevalence of metabolic syndrome and its individual components in Psoriatic patients and compare them with age and sex matched controls. Methods: The study included 60 psoriatic patients and 60 age and sex matched controls. Severity of psoriasis was assessed according to psoriasis area and severity index (PASI) score. Waist circumference, blood pressure, fasting plasma glucose, serum cholesterol, HDL, LDL, VLDL and triglycerides were recodrded in all patients and controls. Metabolic syndrome was diagnosed by the presence of three or more of the five criteria of the 2005 revised National Cholesterol Education Programme's Adult Treatment Panel III . Statistical analysis of the data was performed. Results: Prevalence of metabolic syndrome was seen in 20 cases $(33.3 \%)$ compared to $9(15 \%)$ controls which was statistically significant $(P=0.019)$. Metabolic syndrome, high fasting blood glucose, high triglyceride levels and low HDL levels were significantly more in cases than controls. There was no significant difference in the prevalence of abdominal obesity and hypertension among cases and controls. Conclusion: There is a need for regular evaluation of psoriatic patients, even younger patients and those with mild disease, for the presence of any of the components of metabolic syndrome. Dermatologists should screen all psoriasis patients to detect the existence of comorbid conditions such as metabolic syndrome and its individual components.
\end{abstract}

Key words: Psoriasis, Metabolic Syndrome, Hyperlipidemia, Obesity.

\section{Introduction}

Psoriasis is a common, chronic immune mediated inflammatory disease of the skin characterized by well demarcated, infiltrated, erythematous, scaly plaques that may be limited or widespread in extent having profound effect on quality of life of patients [1,2]. Beyond a debilitating skin ailment, often associated with a large negative impact on health related quality of life, psoriasis may act as an external indicator of underlying immune and metabolic dysregulation and is linked with a number of behavioural and systemic comorbidities including metabolic syndrome [3,4]. Metabolic syndrome is a cluster of risk factors including central obesity, atherogenic dyslipidemia, hypertension and glucose intolerance and is a strong predictor of cardiovascular disease. It confers a cardiovascular risk higher than individual components [5].

Recently, associations between psoriasis and metabolic disorders such as obesity, diabetes, and atherogenic dyslipidemia have been recognized. Moreover, an

Manuscript received: $3^{\text {rd }}$ Apr 2015

Reviewed: $12^{\text {th }}$ Apr 2015

Author Corrected: $16^{\text {th }}$ Apr 2015

Accepted for Publication: $30^{\text {th }}$ Apr 2015

International Journal of Medical Research and Review increased mortality from cardiovascular disease in patients with severe psoriasis has been documented and psoriasis may confer an independent risk of myocardial infarction especially in hospitalized young patients. These diseases share a common pathophysiological link permitting them to join atherosclerosis and consequent cardiovascular disease $[6,7,8]$. The present study was performed to know the prevalence of metabolic syndrome in Psoriatic patients of north coastal Andhra Pradesh and also the prevalence of individual components of syndrome and compare them with age and sex matched controls.

\section{Materials and Methods}

The study was conducted at the department of Dermatology of a suburban medical college hospital over a period of 18 months from January 2012 to June 2013 after being approved by Institutional Ethics Committee. The study was a prospective, hospital based case control study involving 60 psoriatic patients diagnosed clinically and 60 age and sex matched controls. Patients with clinical diagnosis of psoriasis within the age group of $20-$ 70 years and of both sexes with a disease duration of at least six months were included in the study. The controls

Available online at: www.ijmrr.in 404 | P a g e 
Research Article

were patients with dermatoses other than psoriasis attending the dermatology outpatient department. Patients receiving any systemic treatment for psoriasis including acitretin, methotrexate, ciclosporin, phototherapy or biologics for at least 1 month before enrolment were excluded from the study.

After obtaining informed consent, general data regarding age, sex, weight, height, waist circumference, blood pressure, smoking habit, alcohol consumption, duration of disease, type and severity of psoriasis, history of treatment and family history were noted. Severity of psoriasis was assessed according to psoriasis area and severity index (PASI) score, a composite score that evaluates the erythema, induration and scaling of lesions in four body areas (head, trunk, arms and legs)[1]. To measure waist circumference, top of right iliac crest was located and the measuring tape was placed snugly in a horizontal plane around the abdomen at the level of iliac crest.

The blood pressure was measured using manual mercury sphygmomanometer. Two recordings were taken in the sitting position at an interval of 5 minutes. The average of the 2 readings was taken as the final measurement. Venous samples were taken from all patients and controls after an overnight fast of at least 8 hours. Plasma fasting glucose was measured using a glucose oxidase method. Serum cholesterol, HDL, LDL, VLDL and triglycerides were measured with enzymatic procedures.

Metabolic syndrome was diagnosed by the presence of three or more of the five criteria of the 2005 revised National Cholesterol Education Programme's Adult Treatment Panel III (NCEP ATP III)[9] (Table1). Statistical analysis of the data was performed by using Statistical Package for Social Sciences (SPSS) trial version 17. Numerical and graphical techniques have been used to summarize and present the quantitative data of this study. Data was represented in the form of frequencies and percentages with the help of tables. To test the statistical difference between proportions, chi square test was used and $\mathrm{p}$ value less than 0.05 was taken as statistically significant.

Table 1: Criteria for clinical diagnosis of metabolic syndrome

\begin{tabular}{|l|l|}
\hline $\begin{array}{l}\text { Measure (any } 3 \text { of } 5 \text { constitute diagnosis of } \\
\text { metabolic syndrome) }\end{array}$ & Cut off points \\
\hline Elevated waist circumference & $\begin{array}{l}\geq 90 \mathrm{~cm} \text { for South Asian men, } \\
\geq 80 \mathrm{~cm} \text { for South Asian women }\end{array}$ \\
\hline Elevated triglycerides & $\begin{array}{l}\geq 150 \mathrm{mg} / \mathrm{dl} \text { or } \\
\text { on drug treatment for elevated triglycerides }\end{array}$ \\
\hline Reduced HDL cholesterol & $<40 \mathrm{mg} / \mathrm{dl}$ in men, $<50 \mathrm{mg} / \mathrm{dl}$ in women \\
& or \\
& on drug treatment for reduced HDLcholesterol \\
\hline Elevated blood pressure & $\begin{array}{l}\geq 130 \mathrm{~mm} \text { Hg systolic blood pressure or } \\
\geq 85 \mathrm{~mm} \text { diastolic blood pressure or } \\
\text { On antihypertensive drug treatment in a patient with a history } \\
\text { of hypertension }\end{array}$ \\
\hline Elevated fasting blood glucose & $\geq 100 \mathrm{mg} / \mathrm{dl}$ or on drug treatment for elevated glucose \\
\hline
\end{tabular}

\section{Results}

Out of the 60 psoriasis cases, 41( 68.3\% ) were males and 19 (31.7\%) were females with a male to female ratio of $2.16: 1$. The age of the patients varied from 21 - 69 years, the mean age being 40.6 years ( $\mathrm{SD}=7.28$ yrs). Majority of the psoriatic patients belonged to the age group of 30-39 years (30\%) followed by the age group of 40-49 years (23.3\%). Twenty nine patients $(48.3 \%)$ had a disease duration from 6 months to 5 years and 31(51.7\%) had the disease for more than 5 years. Psoriasis Area and Severity Index score ranged from 4 to 68.8. The mean PASI score was 18.463. Fifty percent of the cases had PASI score between 10.1 to 20 .

Table 2: Prevalence of metabolic syndrome among cases and controls $(n=120)$

\begin{tabular}{|c|c|c|c|}
\hline Metabolic syndrome & Cases & Controls & \multirow{4}{*}{$\begin{array}{l}\chi^{2} \text { value }=5.502 \\
\mathrm{df}=1 \\
\mathrm{p} \text { value }=0.019^{*}\end{array}$} \\
\hline Present & $20(33.3 \%)$ & $9(15 \%)$ & \\
\hline Absent & $40(66.7 \%)$ & $51(85 \%)$ & \\
\hline Total & $60(100 \%)$ & $60(100 \%)$ & \\
\hline
\end{tabular}


df: degrees of freedom; $* \mathrm{p}<0.05$ statistically significant.

Prevalence of metabolic syndrome was seen in 20 cases $(33.3 \%)$ compared to $9(15 \%)$ controls which was statistically significant $(P=0.019)$.

Prevalence of abdominal obesity (waist circumference $\geq 90 \mathrm{~cm}$ in males, $\geq 80 \mathrm{~cm}$ in females) was seen in 20 cases (33.3\%) and 13 controls $(21.7 \%)$ which was statistically insignificant $(P=0.152)$. There was no significant difference in the prevalence of hypertension among cases (19) and controls (11) $(P=0.092)$. Increased fasting blood glucose levels $(\geq 100$ $\mathrm{mg} / \mathrm{dl})$ were observed in $21(35 \%)$ psoriatic patients and $9(15 \%)$ controls which was statistically significant $(P=0.011)$. Significantly higher prevalence of high triglyceride levels $(\geq 150 \mathrm{mg} / \mathrm{dl})$ was observed in cases $(26)$ than controls $(12)(P=$ 0.006). Low HDL levels ( $<40 \mathrm{mg} / \mathrm{dl}$ in males, $<50 \mathrm{mg} / \mathrm{dl}$ in females) were more common in psoriatic patients than in controls (33 cases $(55 \%)$ Vs 15 control $(25 \%)$. This difference was statistically highly significant $(P=0.001)$.

Table 3: Prevalence of metabolic syndrome and its components among cases and controls $(\mathbf{n}=120)$

\begin{tabular}{|l|l|l|l|}
\hline $\begin{array}{l}\text { Metabolic syndrome \& its } \\
\text { components }\end{array}$ & Cases & Controls & P value $^{*}$ \\
\hline Metabolic syndrome & $20(33.3 \%)$ & $9(15 \%)$ & 0.019 (significant) \\
\hline Abdominal obesity & $20(33.3 \%)$ & $13(21.7 \%)$ & 0.152 (not significant) \\
\hline Hypertension & $19(31.7 \%)$ & $11(18.3 \%)$ & 0.092 (not significant) \\
\hline High fasting blood glucose & $21(35 \%)$ & $9(15 \%)$ & 0.011 (significant) \\
\hline High triglyceride levels & $26(43.3 \%)$ & $12(20 \%)$ & 0.006 (highly significant) \\
\hline Low HDL levels & $33(55 \%)$ & $15(25 \%)$ & 0.001 (highly significant) \\
\hline
\end{tabular}

$* \mathrm{p}<0.05$ statistically significant $\mathrm{p}<0.01$ statistically highly significant

Among psoriatic patients, there was no significant difference in the occurrence of metabolic syndrome between males (13) and females (7) $(P=0.695)$. Among psoriatic patients, 15 out of the 28 patients $(53.6 \%)$ in the age group of more than 40 years had metabolic syndrome whereas 5 out of the 32(15.6\%) patients in the age group of 40 and below had metabolic syndrome which was statistically highly significant $(P=0.002)$. There was no significant difference in the occurrence of metabolic syndrome among cases with duration of disease more than 5 years (13) and cases with duration of disease between 6 months to 5 years $(7)(P=0.144)$. There was no significant difference in the prevalence of metabolic syndrome among cases with PASI score more than $12(31.7 \%)$ and cases with PASI score 12 and below $(36.8 \%)(P=0.695)$. To summarize, metabolic syndrome, high fasting blood glucose, high triglyceride levels and low HDL levels were significantly more in cases than controls. There was no significant difference in the prevalence of abdominal obesity and hypertension among cases and controls (Table 3).

\section{Discussion}

Gerald Reaven, an endocrinologist from Stanford University, first described the Metabolic Syndrome in 1988. It was originally described as the clustering of four conditions that when present together in one individual increased the risk of cardiovascular disease. The four conditions were glucose intolerance, hypertension, dyslipidemia and central obesity [5,9]. Chronic inflammation of skin in psoriasis predisposes patients to a state of increased risk for cardio-metabolic disease [10]. In 2006, Mallbris et al. and Sommer et al showed that Metabolic syndrome was more prevalent in psoriasis patients [11,12]. Since then, similar evidence of association of psoriasis with metabolic syndrome has been found in many studies from various parts of the world including India $[6,7,8,13]$.

A high prevalence of metabolic syndrome is seen in Indians and psoriasis could represent an additional source

International Journal of Medical Research and Review of morbidity due to its positive association with metabolic syndrome $[13,14]$. In the present study, the prevalence of metabolic syndrome was more in psoriatic patients than controls $(33.3 \%$ Vs $15 \%)$ which was statistically significant $(P=0.019)$ and in accordance with prevous studies by Cohen et al and Sommer et al [7,12]. In the present study, statistically significant association was not observed between duration and severity of psoriasis and occurrence of metabolic syndrome but it was significantly more prevalent after the age of 40 years, similar to findings of the studies by Nisa et al. and Gisondi et al $[14,15]$

The combination of obesity and psoriasis is an important health care concern. Both conditions are associated with chronic inflammation, which may exacerbate the cardiovascular disease pathogenic process such as atherosclerosis. Lifestyle factors such as decreased Available online at: www.ijmrr.in 406 | P a g e 


\section{Research Article}

physical activity due to social stigma, depression and increased alcohol consumption may further exacerbate the obesity in psoriatic patients [16]. In the present study, there was no significant difference in the prevalence of abdominal obesity among cases and controls (33.3\% Vs $21.7 \%)(P=0.152)$ similar to the findings of Nisa et al and Takahashi et al [14,17]. Studies have revealed that diabetes is an increasingly reported comorbidity with psoriasis, independent of factors such as obesity, hypertension, and hyperlipidemia. A possible explanation for the association between psoriasis and diabetes is the presence of chronic inflammation that occurs due to persistent secretion of TNF- $\alpha$ and other proinflammatory cytokines such as IL-1 and IL-6, which precipitates both psoriasis and diabetes. Prevalence of high fasting blood sugars was more in psoriasis patients than controls [35\% vs. $15 \%$ ] and the difference was statistically significant and in agreement with the studies by Madanagobalane and Anandan, Nisa et al, Takahashi et al and Alsufyani $[13,14,17,18]$.

Lipid abnormalities were observed in psoriatic patients and several factors including unhealthy lifestyle, Th1 inflammation which induces endothelial dysfunction, antibodies recognizing oxidized LDL and certain medications used to treat psoriasis such as oral retinoids and cyclosporine may induce dyslipidemia $[19,20]$. In the present study, raised serum triglycerides levels were more in psoriatic patients than in controls $(43.3 \%$ vs. $20 \%)$ and the difference was statistically significant $(P=0.006)$. In the present study, low HDL levels were significantly more in psoriatic patients than in controls (55\% vs. 25\%). This finding was in contrast to studies by Madanagobalane et al (36.4\% vs. $67.5 \%)$ and Nisa et al (56.7\% vs. $62.7 \%)$. These studies did not show any statistical difference in the prevalence of low HDL levels among psoriatic patients and controls.

To conclude, we have observed in our study that occurrence of metabolic syndrome in psoriasis is independent of the severity and duration of disease which emphasizes the need for regular evaluation of psoriatic patients, even younger patients and those with mild disease, for the presence of any of the components of metabolic syndrome. Dermatologists should not just recognize and treat the signs and symptoms of psoriasis but should also screen patients to detect the existence of comorbid conditions such as metabolic syndrome and its individual components. A multidisciplinary approach, with coordination between dermatologists and other specialists, is needed to recognize and treat any comorbities, minimize co-medication, prevent complications and improve the quality of life of psoriasis patients.
Funding: Nil, Conflict of interest: None initiated. Permission from IRB: Yes

\section{References}

1. Gelfand JM, Weinstein R, Porter SB, Neimann AL, Berlin JA, Margolis DJ. Prevelance and treatment of psoriasis in the United Kingdom: A population-based study. Arch Dermatol. 2005Dec;141(12):1537-41.

2. Schon MP, Boehncke WH. Psoriasis. N Engl J Med 2005 May 5;352(18):1899-912..

3. Henseler T, Christophers E. Disease concomitance in psoriasis. J Am Acad Dermatol. 1995 Jun;32(6):982-6.

4. Rocha-Pereira P, Santos-Silva A, Rebelo I, Figueiredo A. The inflammatory response in mild and in severe psoriasis. Br J Dermatol 2004 May;150(5):917-28.

5. Grundy SM, Cleeman JI, Daniels SR, Donato KA, Ecke RH, Franklin BA, et al. Diagnosis and Management of the Metabolic Syndrome. Circulation 2005 Oct 25;112(17):2735-52.

6. Gelfand JM, Neimann AN, Shin DB, Wang X, Margolis DJ, Troxel AB. Risk of myocardial infarction in patients with psoriasis. JAMA 2006 Oct 11;296(14):1735$41 .$.

7. Cohen AD, Sherf M, Vidavsky L, Vardy DA, Shapiro J, Meyerovitch J. Association between psoriasis and the metabolic syndrome. Dermatol 2008;216(2):152-5.

8. Neimann AL, Shin DB, Wang X, Margolis DJ, Troxel AB, Gelfand JM. Prevalence of cardiovascular risk factors in patients with psoriasis. J Am Acad Dermatol 2006 Nov;55(5):829-35.

9. Alberti KG, Zimmet P, Shaw J. IDF Epidemiology Task Force Consensus Group. The metabolic syndrome: A new worldwide definition. Lancet 2005 Sep 2430;366(9491):1059-62.

10. Christophers E, Mrowietz U. Psoriasis. In: Burgdorf WHC, Plewig G, Wolff HH, Landthaler M, editors. Dermatology. ${ }^{3 \text { rd }}$ ed. Heidelberg: Springer Medizine Verlag; 2009. p. 507.

11. Mallbris L, Granath F, Hamsten A, Stahle M. Psoriasis is associated with lipid abnormalities at the onset of skin disease. J Am Acad Dermatol 2006 Apr;54(4):614-21. 
12. Sommer DM, Jenisch S, Suchan M, Christophers E, Weichental M. Increased prevalence of metabolic syndrome in patients with moderate to severe psoriasis. Arch Dermatol Res 2006 Dec;298(7):321-8.

13. Madanagobalane S, Anandan S. Prevalence of metabolic syndrome in South Indian patients with psoriasis vulgaris and the relation between disease severity and metabolic syndrome: A hospital-based casecontrol study. Indian J Dermatol 2012;57:353-7

14. Nisa N, Qazi MA. Prevalence of metabolic syndrome in patients with psoriasis. Indian J Dermatol Venereol Leprol 2010 Nov-Dec;76(6):662-5.

15. Gisondi P, Tessari G, Conti S, Piaserico S, Schianchi $\mathrm{S}$, Peserico A, et al. Prevalence of metabolic syndrome in patients with psoriasis: A hospital - based case - control study. Br J Dermatol 2007 Jul;157(1):68-73.

\section{Research Article}

16. Sterry W, Strober BE, Menter A. Obesity in psoriasis: The metabolic, clinical and therapeutic implications. Report of an interdisciplinary conference and review. Br J Dermatol 2007 Oct;157(4):649-55.

17. Takahashi H, Iizuka H. Psoriasis and metabolic syndrome. J Dermatol 2012 Mar;39(3):212-8 .

18. Alsufyani MA, Golant AK, Lebwohl M. Psoriasis and the metabolic syndrome. Dermatol Ther 2010 MarApr;23(2):137-43.

19. Pietrzak A, Chodorowska G, Szepietowski J, Zalewska-Janowska A, Krasowska D, Hercogová J. Psoriasis and serum lipid abnormalities. Dermatol Ther 2010 Mar-Apr;23(2):160-73.

20. Vena GA, Vestita M, Cassano N. Psoriasis and cardiovascular disease. Dermatol Ther 2010 MarApr;23(2):144-51.

\section{How to cite this article?}

K.V.T. Gopal, G. Deepika Raj, T. Narayana Rao. Prevalence of metabolic syndrome in Psoriasis - a case control study. Int J Med Res Rev 2015;3(4):404-408. doi: 10.17511/ijmrr.2015.i4.079. 